\title{
ANALISIS JARINGAN KERJA PADA EVALUASI PENJADWALAN WAKTU DAN BIAYA PENYELESAIAN PROYEK DENGAN MENGGUNAKAN METODE PERT \& CPM
}

\author{
Dhonna Febby Lintang Asri“, Tabah Heri Setiawan, dan Yulianti Rusdiana \\ ${ }^{1)}$ Program Studi Matematika, Fakultas Matematika dan Ilmu Pengetahuan Alam, Universitas Pamulang. \\ J1. Raya Puspiptek, Buaran, Kec. Pamulang, Kota Tangerang Selatan, Banten. \\ *dhonnafebby@gmail.com
}

\begin{abstract}
PERT and CPM are a method that aims to minimize the occurrence of disruptions and delays in the production stage so that they can evaluate the scheduling of time and cost in project completion. The final project discusses the PERT method and CPM in evaluating the time and costs determined by CV. Mitra Data Perkasa is working on an inactive archive management project. This research gets the fastest time in project completion using critical path for 80 working days. The results of scheduling evaluations with PERT and CPM methods get good results in accelerating project completion.
\end{abstract}

Keywords: Critical Path, PERT \& CPM, Time.

\begin{abstract}
ABSTRAK
PERT dan CPM merupakan suatu metode yang bertujuan untuk meminimalisir adanya gangguan dan penundaan dalam tahap produksi sehingga dapat mengevaluasi penjadwalan waktu dan biaya dalam penyelesaian proyek. Tugas Akhir ini membahas tentang metode PERT dan CPM dalam mengevaluasi waktu dan biaya yang telah ditentukan oleh CV. Mitra Data Perkasa dalam pengerjaan proyek pengelolaan arsip inaktif. Penelitian ini mendapatkan waktu tercepat dalam penyelesaian proyek dengan menggunakan jalur kritis (critical path) selama 80 hari kerja. Hasil evaluasi penjadwalan dengan metode PERT dan CPM memperoleh hasil yang baik dalam mempercepat penyelesaian proyek.
\end{abstract}

Kata kunci: Critical Path, PERT \& CPM, Waktu

\section{PENDAHULUAN}

Perkembangan teknologi yang semakin pesat membuat kebutuhan akan suatu aplikasi sangat dibutuhkan dalam menunjang kemudahan dalam sebuah pekerjaan. Perusahaan-perusahaan swasta maupun BUMN menggunakan teknologi sebagai media untuk menyelesaikan pekerjaan yang sederhana maupun rumit. Dalam kegiatan keadministrasian, perusahaan tidak lepas dari data-data yang dibuat dalam mendukung kegiatan perekonomiannya.

Data dibuat sebagai media dalam perekaman aktivitas atau peristiwa yang sedang atau telah dilakukan dalam lingkungan perusahaan. Data-data ini disebut dengan arsip. Perusahaan sebagai pencipta arsip membutuhkan pengolahan keadministrasian yang 
teratur dan rapi. Arsip merupakan informasi yang mengandung peristiwa sejarah kegiatan yang dilakukan dalam organisasi maupun perusahaan. Sedangkan, informasi mengenai peristiwa dalam organisasi yang disajikan dalam bentuk persuratan maupun audio visual atau biasa disebut dengan file dengan rentan masa berlaku telah dinyatakan berakhir atau lebih dari 5 (lima) tahun berdasarkan dengan jenis dokumen itu sendiri, selanjutnya dilakukan pengolahan dengan sistem pendataan, maka hal ini dapat dikatakan dengan pengolahan arsip inaktif.

Pelayanan dan pengorganisasian yang baik dalam menciptakan suatu kegiatan kearsipan dapat memberikan kontribusi penyelarasan suatu nilai estetika pada pengelolaan sebuah dokumen. Dalam hal ini menuntut bagian pengolah arsip untuk lebih terorganisir menjaga dan mengolah arsip-arsip tersebut. Arsip merupakan bagian yang penting, sehingga menyebabkan perusahaan menggunakan jasa konsultan arsip dalam mengelola arsip yang telah dinyatakan inaktif. Jasa konsultan arsip memberikan kemudahan dan alternatif dalam meringankan kinerja bagian kearsipan suatu perusahaan untuk mengolah arsip inaktif.

Tata cara dalam pengelolaan arsip inaktif yang dilakukan oleh CV. Mitra Data Perkasa dilakukan dengan beberapa tahap, mulai dari pemilahan dokumen, pemberkasan, pendeskripsian, selanjutnya input data, kemudian menggolongkan data secara fisik, membuat daftar arsip, pelabelan kotak (boks arsip) dan yang terakhir penataan boks arsip pada rak, sehingga hal ini menjadi kegiatan yang dilakukan dalam setiap menjalankan proyek pengolahan arsip inaktif.

Waktu pengerjaan proyek pengelolaan arsip dilakukan antara 5 sampai 6 bulan, sesuai dengan waktu yang telah ditentukan oleh konsumen. Namun, dalam kenyataannya, terkadang waktu untuk penyelesaian proyek tersebut melebihi yang telah ditentukan. Hal ini dikarenakan kegiatan pengerjaan proyek yang kurang teratur, sehingga dibutuhkan tambahan waktu untuk menyelesaikan proyek tersebut. Hal ini menyebabkan biaya yang keluar juga ikut bertambah dari anggaran yang telah ditentukan diawal. Tambahan waktu (Overtime) ini menyebabkan perusahaan terkena pinalti dari perjanjian yang telah disepakati, sehingga anggaran yang dikeluarkan CV. Mitra Data Perkasa menjadi lebih besar.

Berdasarkan uraian di atas, penulis melakukan analisis tentang jaringan kerja dengan mengevaluasi penjadwalan waktu dan biaya penyelesaian proyek. Dalam penelitian ini 
menggunakan metode Project Evaluation and Review Technique (PERT) dan Critical Path Method (CPM).

\section{METODOLOGI}

Jenis data yang digunakan merupakan data primer dan sekunder. Data diperoleh dengan melakukan wawancara dengan pimpinan perusahaan tentang kegiatan, waktu dan biaya proyek, mempelajari uraian yang didapat dari studi pustaka. Penelitian dilakukan pada bulan April sampai dengan Juli 2019 pada CV. Mitra Data Persada.

Mencatat lebih detail setiap proses produksi untuk lebih mengetahui proses supaya kualitas semakin lebih meningkat. (Aden dan Setiawan, Tabah Heri: 2019). Adapun yang dijadikan penelitian adalah kegiatan yang dilakukan selama proses pengerjaan proyek pengelolaan arsip inaktif yang dilakukan CV. Mitra Data Perkasa. Terdapat sepuluh kegiatan untuk menyelesaikan proyek pengelolaan arsip inaktif, diantaranya Persiapan/ Survei (A) yaitu melakukan survei dengan menghitung luas area yang akan dilakukan pengelolaan arsip, Perekrutan Pegawai (B) yaitu merekrut pegawai part time untuk pengerjaan proyek, Pelatihan Pegawai (C) yaitu memberikan pelatihan kepada pegawai baru dalam mengerjakan pengelolaan arsip secara bertahap, Pemilahan Dokumen (D) yaitu memisahkan jenis dokumen yang merupakan arsip dan non arsip, Pemberkasan (E) yaitu mengelompokkan berkas dokumen sesuai dengan klasifikasi arsip, Pendeskripsian (F) yaitu melakukan input data dengan berisikan informasi yang terdapat pada setiap dokumen, Manuver Data (G) yaitu melakukan pemindahan atau penyortiran data sesuai dengan klasifikasinya, Pembuatan Daftar Arsip (H) yaitu membuat daftar apa saja arsip yang telah dilakukan pengelolaan dan menjadi arsip inaktif untuk selanjutnya dilakukan pelabelan, Pelabelan (I) yaitu proses dimana memberikan label boks dengan tujuan untuk memberikan nomor pada setiap boks yang ada sehingga memudahkan arsiparis dalam mencari dokumen yang terdapat pada salah satu boks dan yang terakhir Penataan boks ke dalam rak (J) yaitu penataan boks untuk merapikan dan mengurutkan nomor boks yang telah dilakukan pengelolaan arsip.

Analisis penelitian ini dengan menggunakan Metode PERT dan CPM dalam menentukan waktu dan biaya penyelesaian proyek. Sistematika proses PERT dan CPM sebagai berikut: 
1. Mengumpulkan dan mengamati lingkup proyek, menguraikan menjadi kelompok masalah. Data sekunder yang berupa data kegiatan pekerjaan yang akan diidentifikasi.

2. Setelah data terkumpul dan diidentifikasi, selanjutnya melakukan analisis jaringan kerja dengan metode PERT dan CPM [Wijaya, 2013:185].

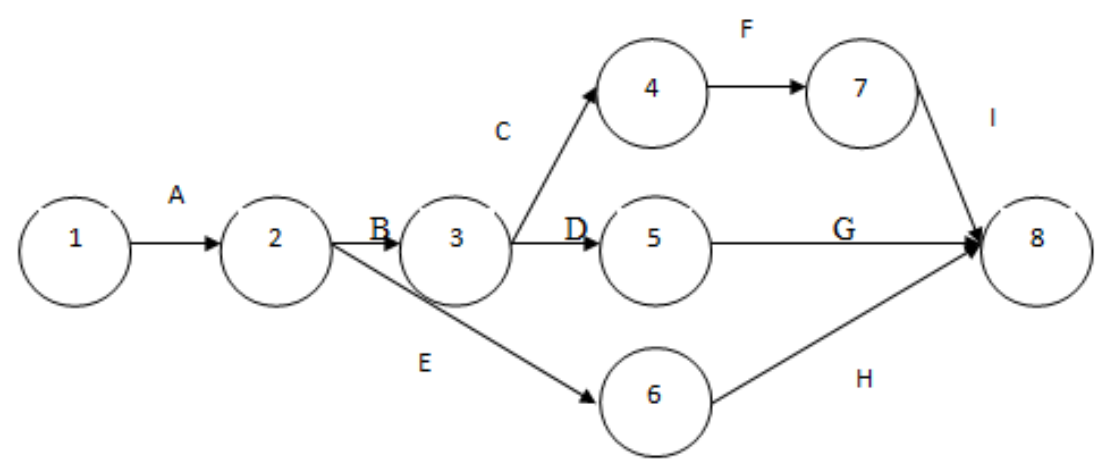

Gambar. 2.1. Jaringan Kerja

3. Menghitung ES dengan perhitungan maju, EF, LS, dan LF dengan menggunakan perhitungan mundur.

$$
\begin{aligned}
& D_{i j}=\text { lama waktu yang diperlukan setiap kegiatan }(i, j) \\
& E S_{j}=\operatorname{maks}_{i}\left\{E S_{i}+D_{i j}\right\} \text { untuk seluruh kegiatan }(i, j) \text { di mana seperti disebutkan }
\end{aligned}
$$
$E S_{1}=0$. Untuk dapat menghitung $E S_{j}$ pada kejadian $j$, semua $E S_{i}$ harus dihitung, misalnya jika ada lebih dari satu kegiatan yang menuju kejadian $j$.[Supranto, 2006:252]

Rumus $L F_{i}$ dari satu simpul $i$ ke beberapa simpul $j$.

$$
L F_{i}=\min _{j}\left\{L F_{j}-D_{i j}\right\}
$$

$\mathrm{LS}=$ waktu mulai paling lambat (the latest start), $\mathrm{EF}=$ waktu penyelesaian paling cepat (earliest finish) untuk kegiatan $(i, j)$, berikut rumusnya:

$$
\begin{aligned}
& L S_{i j}=L F_{j}-D_{i j} \\
& E F_{i j}=E S_{i}+D_{i j}
\end{aligned}
$$

4. Menentukan lintasan kritis dari jaringan kerja yang telah dilakukan penghitungan ES, EF, LS dan LF dengan mempertimbangkan berdasarkan syarat yang ditentukan. 
Perhitungan ES dan LF telah semuanya dihitung, selanjutnya suatu kegiatan $(i, j)$ dikatakan terletak pada jalur kritis dan menjadi kegiatan yang kritis, apabila memenuhi syarat sebagai berikut:

$$
\begin{aligned}
& \text { (i) } E S_{i}=L F_{i}, \\
& \text { (ii) } E S_{j}=L F_{j}, \\
& \text { (iii) } E S_{j}-E S_{i}=L F_{j}-L F_{i}=D_{i j} \text {, }
\end{aligned}
$$

5. Selanjutnya menghitung waktu penjadwalan dan biaya normal dan dipercepat dari penyelesaian proyek.

6. Mengitung waktu yang diharapkan (te), dengan menggunakan pendekatan distribusi beta sebagai berikut[Wijaya, 2013:190]:

$$
t e=\frac{a+4 m+b}{6}
$$

7. Menghitung risiko dengan menggunakan pendekatan variansi dan standar deviasi, berikut penghitungannya:

$$
v_{i j}=\sigma^{2}=\left(\frac{b-a}{6}\right)^{2} \text { dan } \sigma=\sqrt{v}
$$

8. Menghitung biaya tambahan yang dikeluarkan perusahaan untuk melakukan percepatan penyelesaian suatu proyek dapat dihitung dengan cara di bawah ini:

Biaya tambahan $($ incremental cost $)=\frac{\Delta C}{\Delta T}=\frac{C_{1}-C_{0}}{T_{1}-T_{0}}$

9. Menghitung probabilitas proyek dengan lamanya waktu waktu yang diharapkan, dengan cara[Wijaya, 2013:190]:

$$
Z=\frac{D-T S}{\sigma}
$$

\section{PEMBAHASAN}

\subsection{Hasil Penelitian}

Data penelitian yang diambil adalah data primer dan data sekunder yang di dapatkan dari hasil wawancara dan observasi pada CV. Mitra Data Perkasa, yaitu data kegiatan dan durasi waktu pengerjaan proyek serta anggaran biaya yang dikeluarkan selama penyelesaian proyek. Adapun data yang diperoleh sebagai berikut: 
Berikut data kegiatan dan durasi waktu penyelesaian proyek

Tabel. 3.1 Data Kegiatan dan Waktu

\begin{tabular}{ccc}
\hline Kegiatan & Kegiatan Pendahulu & Durasi Waktu \\
\hline A & - & 1 (satu) hari \\
B & A & 1 (satu) hari \\
C & B & 7 (tujuh) hari \\
D & A & 8 (delapan) hari \\
E & C, D & 5 (lima) hari \\
F & C, D & 57 (lima puluh tujuh) hari \\
G & E & 8 (delapan) hari \\
H & F & 6 (enam) hari \\
I & G, H & (empat) hari \\
J & I & 4 (empat) hari \\
\hline Total & & 101 (seratus satu) hari \\
\hline
\end{tabular}

Keterangan:
A : Persiapan/ Survei
B : Perekrutan Pegawai
C : Pelatihan Pegawai
D : Pemilahan Dokumen
E : Pemberkasan
F : Pendeskripsian
G : Manuver Data
H : Pembuatan Daftar Arsip
I : Pelabelan
J : Penataan Boks Ke Rak

Berikut ini anggaran biaya yang digunakan untuk melancarkan proses pengerjaan proyek yang dijalankan:

Tabel 3.2 Anggaran Biaya Proyek

\begin{tabular}{|c|c|c|c|c|}
\hline No & Keterangan & Jumlah & Per Bulan & Total 5 Bulan \\
\hline 1 & Biaya Gaji & \multirow[t]{6}{*}{7 (tujuh) orang } & Rp 21.000.000,- & Rp 105.000.000,- \\
\hline 2 & Biaya Sewa Mobil & & Rp 10.000.000,- & Rp 50.000.000,- \\
\hline 3 & Biaya BBM & & Rp $1.000 .000,-$ & Rp $\quad 5.000 .000,-$ \\
\hline 4 & Biaya Toll & & Rp 1.200.000,- & 6.000.000,- \\
\hline 5 & Biaya ATK & & Rp $500.000,-$ & 2.500.000,- \\
\hline 6 & Biaya Lain-lain & & Rp 1.000.000,- & Rp 5.000.000,- \\
\hline & Total & & Rp 34.700.000,-- & $\operatorname{Rp} 173.500 .000,-$ \\
\hline
\end{tabular}




\subsection{Pembahasan}

3.2.1. Menghitung secara manual ES, EF, LS, LF, TF dan FF untuk menentukan jalur kritis dari seluruh kegiatan proyek. Perhitungan ini dimulai dari menghitung waktu mulai paling awal (earliest start $=$ ES) menurut Oktrima (2018 : 98-107).

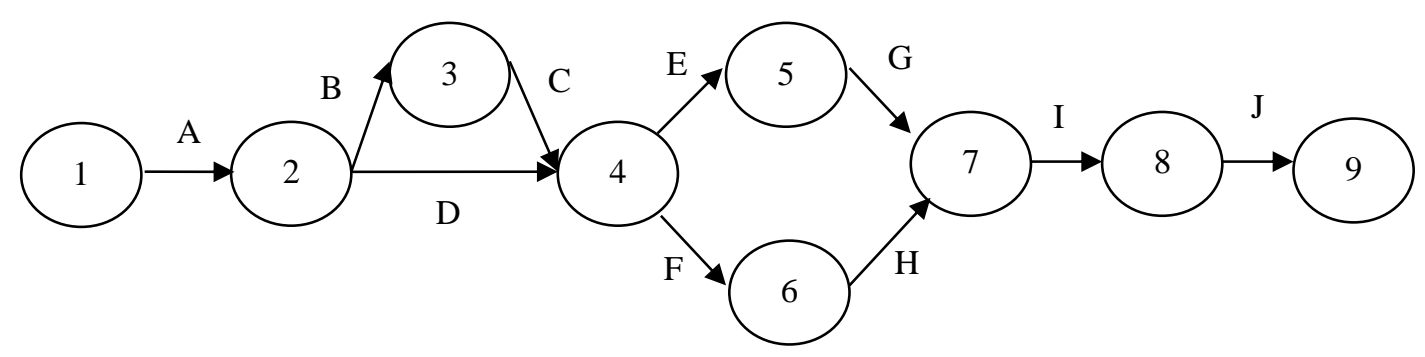

Grafik. 3.1 Diagram Jaringan Kerja

Dari grafik di atas dapat dilakukan penghitungan secara manual untuk menghitung nilai-nilai ES. EF, LS, TF dan FF.

Tabel. 3.3 Perhitungan ES (earliest start)

\begin{tabular}{ccc}
\hline Kejadian & $D_{i j}$ & $E S_{i}$ \\
\hline$(0,1)$ & 0 & 0 \\
$(1,2)$ & 1 & 1 \\
$(2,3)$ & 2 & 2 \\
Maks $(2,4) ;(3,4)$ & $8 ; 7$ & 9 \\
$(4,5)$ & 5 & 14 \\
$(4,6)$ & 57 & 66 \\
Maks $(5,7) ;(6,7)$ & $8 ; 6$ & 72 \\
$(7,8)$ & 4 & 76 \\
$(8,9)$ & 4 & 80 \\
\hline
\end{tabular}

Tabel. 3.4 Perhitungan LF (the latest finish)

\begin{tabular}{cccc}
\hline Kejadian & $D_{i j}$ & $E S_{i}$ & $L F_{i}$ \\
\hline$(0,1)$ & 0 & 0 & 0 \\
$(1,2)$ & 1 & 1 & 1 \\
$(2,3)$ & 2 & 2 & 2 \\
Maks $(2,4) ;(3,4)$ & $8 ; 7$ & 9 & 9 \\
$(4,5)$ & 5 & 14 & 64 \\
$(4,6)$ & 57 & 66 & 66 \\
Maks (5,7); (6,7) & $8 ; 6$ & 72 & 72 \\
$(7,8)$ & 4 & 76 & 76 \\
$(8,9)$ & 4 & 80 & 80 \\
\hline
\end{tabular}


Setelah menghitung ES dan LF untuk menentukan jalur kritis, selanjutnya kita akan menghitung waktu mengambang (slack or float time). Beberapa nilai yang dihitung, yaitu:

1) Total float $=$ kelebihan waktu pada suatu kegiatan sebelum mempengaruhi jalur kritis $(=\mathrm{TF})$. Total float merupakan selisih waktu untuk melakukan suatu kegiatan yang maksimum $\left(L F_{j}-E S_{i}\right)$ dan lama waktu yang diperlukan selama menjalankan setiap kegiatan $D_{i j}$, sebagai berikut:

$$
T F_{i j}=\left(L F_{j}-E S_{i}\right)-D_{i j}=L F_{j}-E F_{i j}=L S_{i j}-E S_{i}
$$

2) Free float $=$ waktu yang bebas pada suatu kegiatan tanpa mengurangi float untuk kegiatan berikutnya. Free float $\left(=F F_{i j}\right)$ pada kegiatan $(i, j)$ merupakan suatu kelebihan waktu $\left(=E S_{j}-E S_{i}\right)$ pada waktu yang diperlukan $\left(=D_{i j}\right)$, yaitu $F F_{i j}=\left(E S_{j}-E S_{i}\right)-D_{i j}$

Tabel. 3.5 Perhitungan ES, EF, LS, LF, TF, FF

\begin{tabular}{lrrrrrrr}
\hline $\begin{array}{c}\text { Kejadian/ } \\
\text { kegiatan }\end{array}$ & $D_{i j}$ & $E S_{i}$ & $E F_{i j}$ & $L S_{i j}$ & $L F_{j}$ & $T F_{i j}$ & $F F_{i j}$ \\
\hline$(1,2) / \mathrm{A}$ & 1 & 0 & 1 & 0 & 1 & $0^{*}$ & 0 \\
$(2,3) / \mathrm{B}$ & 1 & 1 & 2 & 1 & 2 & $0^{*}$ & 0 \\
$(3,4) / \mathrm{C}$ & 8 & 2 & 9 & 2 & 9 & $0^{*}$ & 0 \\
$(2,4) / \mathrm{D}$ & 7 & 1 & 9 & 1 & 9 & $0^{*}$ & 0 \\
$(4,5) / \mathrm{E}$ & 5 & 9 & 14 & 59 & 64 & 50 & 0 \\
$(4,6) / \mathrm{F}$ & 57 & 9 & 66 & 9 & 66 & $0 *$ & 0 \\
$(5,7) / \mathrm{G}$ & 8 & 14 & 22 & 64 & 72 & 50 & 0 \\
$(6,7) / \mathrm{H}$ & 6 & 66 & 72 & 66 & 72 & $0 *$ & 50 \\
$(7,8) / \mathrm{I}$ & 4 & 72 & 76 & 72 & 76 & $0 *$ & 0 \\
$(8,9) / \mathrm{J}$ & 4 & 76 & 80 & 76 & 80 & $0 *$ & 0 \\
\hline
\end{tabular}

*) Kegiatan Kritis 
3.2.2. Menghitung waktu yang diharapkan (te) untuk mengetahui varian dan standar deviasi

Tabel. 3.6 Waktu yang diharapkan (te), varian dan standar deviasi

\begin{tabular}{ccccccc}
\hline \multirow{2}{*}{ Kejadian } & \multicolumn{3}{c}{ Waktu (hari) } & \multirow{2}{*}{ Te } & $v$ & $\sigma$ \\
\cline { 2 - 4 } & $\mathrm{A}$ & $\mathrm{B}$ & $\mathrm{m}$ & & & \multirow{2}{*}{0} \\
\hline$(1,2)$ & 1 & 1 & 1 & 1 & 0 & 0 \\
$(2,3)$ & 1 & 2 & 1 & 1,17 & 0,03 & 0,17 \\
$(3,4)$ & 5 & 8 & 7 & 6,83 & 0,25 & 0,5 \\
$(2,4)$ & 6 & 9 & 8 & 7,83 & 0,25 & 0,5 \\
$(4,5)$ & 3 & 6 & 5 & 4,83 & 0,25 & 0,5 \\
$(4,6)$ & 52 & 57 & 57 & 56,17 & 0,69 & 0,83 \\
$(5,7)$ & 6 & 9 & 8 & 7,83 & 0,25 & 0,5 \\
$(6,7)$ & 4 & 7 & 6 & 5,83 & 0,25 & 0,5 \\
$(7,8)$ & 2 & 5 & 4 & 3,83 & 0,25 & 0,5 \\
$(8,9)$ & 2 & 5 & 4 & 3,83 & 0,25 & 0,5 \\
\hline
\end{tabular}

Dari tabel 3.6 dapat kita lihat perhitungan waktu yang diharapkan dari kejadian yang disebut sebagai jalur kritis adalah $1+1,17+6,83+56,17+5,83+3,83+3,83=78,67$ hari menurut Wardani(2018 : 197-208).

3.2.3. Menghitung percepatan waktu dan biaya

Tabel. 3.7 Biaya Crashing(Percepatan)

\begin{tabular}{|c|c|c|c|c|c|c|}
\hline \multirow{2}{*}{ Kegiatan } & \multicolumn{3}{|c|}{ Waktu } & \multicolumn{2}{|c|}{ Biaya } & \multirow{2}{*}{$\begin{array}{c}\text { Biaya } \\
\text { Crashing } \\
\text { Per Hari }\end{array}$} \\
\hline & Normal & Crashing & Percepat & Normal & Crashing & \\
\hline $\mathrm{A}$ & 1 & 1 & 0 & 1.717 .999 & - & - \\
\hline $\mathrm{B}$ & 1 & 1 & 0 & 1.717 .821 & - & - \\
\hline $\mathrm{C}$ & 7 & 5 & 2 & 12.024 .740 & 15.460 .380 & 1.717 .820 \\
\hline $\mathrm{D}$ & 8 & 7 & 1 & 13.742 .560 & 15.460 .380 & 1.717 .820 \\
\hline $\mathrm{E}$ & 5 & 4 & 1 & 8.589 .100 & 10.306 .920 & 1.717 .820 \\
\hline $\mathrm{F}$ & 57 & 54 & 3 & 97.915 .740 & 103.069 .200 & 1.717 .820 \\
\hline $\mathrm{G}$ & 8 & 6 & 2 & 13.742 .560 & 17.178 .200 & 1.717 .820 \\
\hline $\mathrm{H}$ & 6 & 4 & 2 & 10.306 .920 & 13.742 .560 & 1.717 .820 \\
\hline $\mathrm{I}$ & 4 & 2 & 2 & 6.871 .280 & 10.306 .920 & 1.717 .820 \\
\hline $\mathrm{J}$ & 4 & 3 & 1 & 6.871 .280 & 8.589 .100 & 1.717 .820 \\
\hline
\end{tabular}

Jika menggunakan crashing (percepatan) menurut Wardani (2018 : 197-208), maka:

Pengeluaran = biaya normal + biaya crashing

$=\operatorname{Rp} 173.500 .000,-+(1.717 .820 * 14)$

$=\operatorname{Rp} 173.500 .000,-+\operatorname{Rp} 24.049 .480,-$

$=\mathrm{Rp}$ 197.549.480,- 
Waktu yang telah di crashing menunjukan bahwa ada pengurangan jumlah dari yang dijadwalkan yaitu sebesar 87 hari. Hal ini mengakibatkan adanya pertambahan pada biaya setelah di crashing sebesar Rp 197.549.480,-. Namun crashing ini tidak dapat dilakukan pada pengerjaan proyek ini, karena akan menambahkan biaya dari anggaran yang telah ditetapkan sebesar Rp 173.500.000,-.

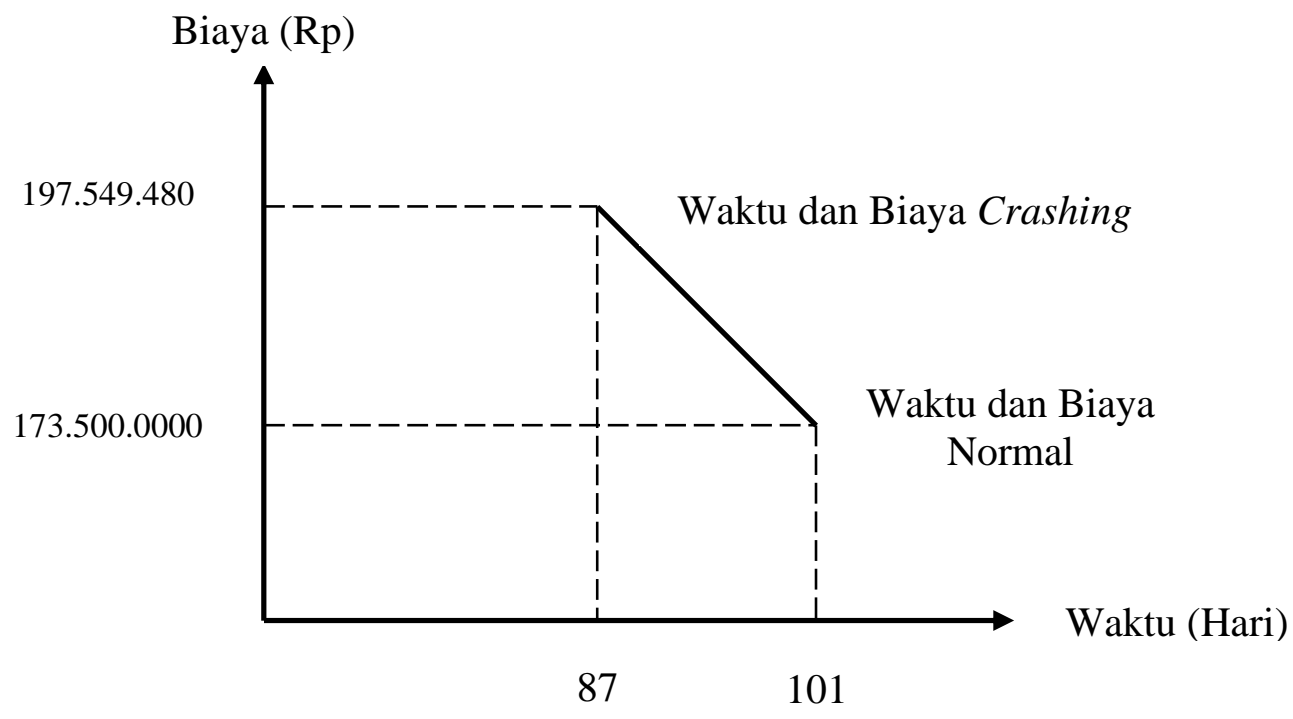

Grafik. 3.2 Hubungan durasi waktu dengan biaya kegiatan

3.2.4. Menghitung probabilitas proyek dengan lamanya waktu waktu yang diharapkan dan standar deviasi:

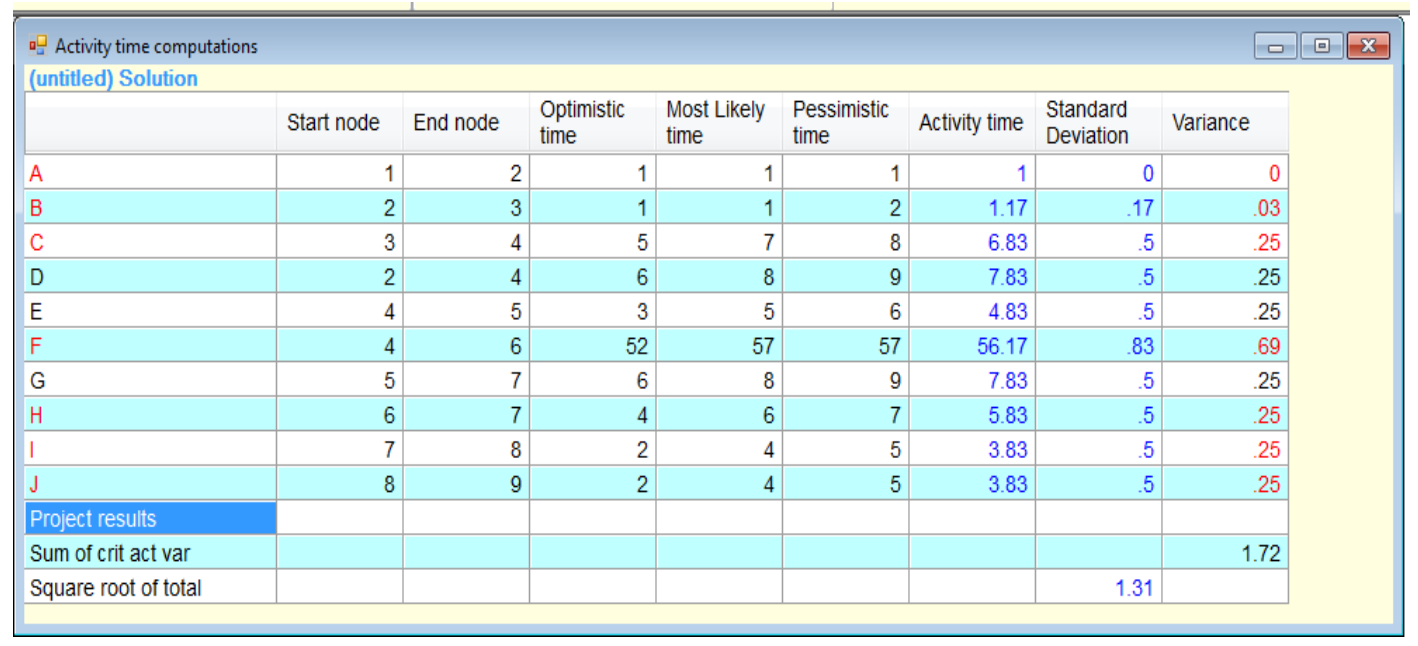

Gambar. 3.1 Activity time computations 
Dapat dilihat dari gambar 3.1, waktu yang diharapkan dengan standar deviasi, menunjukkan:

$\mathrm{D}=80$ hari (=waktu jalur kritis)

$\mathrm{TS}=78,67$ hari $(=$ te $)$

$\sigma=1,31$

$Z=\frac{80-78,67}{1,31}$

$Z=1,02$

Nilai Z telah diperoleh yaitu 1,02 ini membuktikan bahwa probabilitas yang didapat dari nilai 1,02 adalah 0,8461 atau dapat dikatakan 84\%, dengan ini dapat dikatakan proses penjadwalan pengerjaan proyek ini berhasil.

\section{SIMPULAN}

Kesimpulan yang didapat dari penelitian yang dilakukan di atas yaitu:

1. Overtime dapat diatasi dengan penghitungan waktu yang diolah dengan menggunakan metode PERT \& CPM, dengan mencari jalur kritis yang ada pada kegiatan, dilihat dari waktu terpendek dari diagram jaringan kerja yang telah terbentuk. Di mana jalur kritis ini ditandai dengan garis berwarna merah. Jalur kritis ini dimulai dari kegiatan A dilanjutkan ke B ke C (atau langsung melalui D) kemudian dilanjutkan ke F, dilanjutkan kembali $\mathrm{H}$, kemudian ke I dan yang terakhir ke J. dengan adanya jalur kritis ini perusahaan dapat memperhatikan kegiatan mana saja yang harus dikerjakan terlebih dahulu sehingga didapatkan waktu yang terpendek yaitu 80 hari. Dengan waktu 80 hari, perusahaan akan mendapat keuntungan dari total waktu yang telah dijadwalkan 101 hari, karena biaya yang berkurang dan yang mengalami kerugian yaitu karyawan yang berstatus part time.

2. Kegiatan pelaksanaan pengerjaan proyek dapat menjadi lebih teratur dengan kita mendata urutan kegiatan dari proses awal sampai akhir pengerjaan proyek, selanjutnya membuat diagram jaringan kerja. Di situ akan terlihat kegiatan mana saja yang harus diprioritaskan atau diutamakan untuk dilakukan terlebih dahulu sesuai dengan urutannya. 


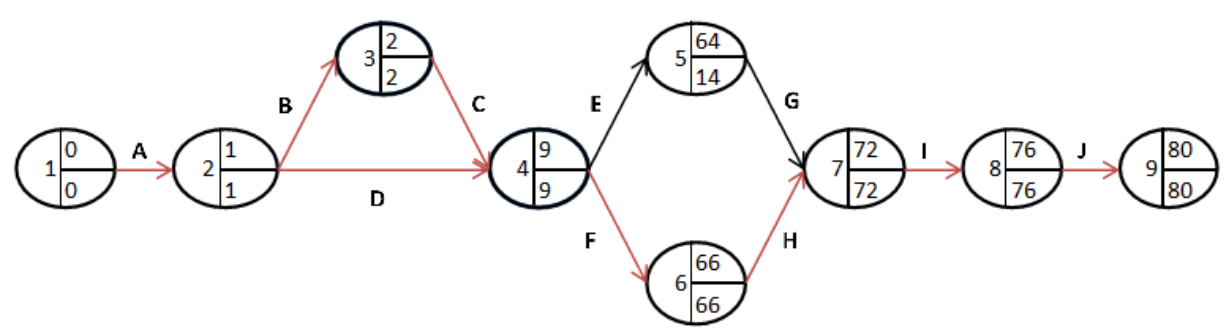

\section{Grafik. 4.1 Diagram Jaringan Kerja da perhitungan metode}

3. Anggaran biaya yang telah dilakukan crashing dengan menggunakan metode PERT dan CPM menjadi Rp 197.549.480,- dengan waktu selama 87 hari. Perusahaan dapat mengambil proyek tersebut dengan memperimbangkan waktu dan biaya tersebut agar tidak terkena pinalti akibat overtime untuk menyelesaikan proyek.

Adapun saran yang dapat disampaikan dalam penelitian ini yaitu sebagai berikut:

1. Saran untuk perusahaan dengan adanya penelitian ini yaitu agar dapat menambah pegawai agar kegiatan yang dilakukan lebih optimal dan tidak memerlukan banyak waktu dalam penyelesain setiap kegiatannya.

2. Saran untuk penelitian selanjutnya agar dapat lebih mengoptimalkan pada proses crashing (percepatan) biaya dan waktu dalam penyelesaian suatu proyek untuk mendapatkan hasil yang paling optimal.

Penelitian ini menekankan pada keberhasilan dalam pembuatan jaringan kerja untuk mendapatkan waktu yang paling cepat sehingga perusahaan mendapatkan keuntungan dengan karyawan part time dalam pengerjaan proyek, sedangkan pada penelitian sebelumnya dilakukan crashing untuk menghemat waktu dan biaya pengerjaan proyek.

\section{DAFTAR PUSTAKA}

Aden, A., \& Setiawan, T. H. (2019). ANALISIS PENGENDALIAN KUALITAS PRODUK ROTI MELALUI KARTU KENDALI PROPORSI (Studi Kasus: CV. Spesial Bakery). STATMAT: JURNAL STATISTIKA DAN MATEMATIKA, $1(1)$.

Oktrima, B., 2018. “Evaluasi Waktu Penyelesaian Proyek dengan Metode PERT (Project Evaluation and Review Technique) di PT. ConcoPhilips Indonesia: Studi Kasus Suban Tie In, April 1-2, 2006”, Jurnal Saintika Unpam, Vol. 1, No.1:98-107. 
Soeharto, I., 2015. Manajemen Proyek Dari Konseptual Sampai Operasional. Jakarta : Penerbit

Supranto, J., 2006. Riset Operasi Untuk Pengambilan Keputusan (Edisi Revisi). Jakarta :

Syaifuddin, Dedy T., 2011. Riset Operasi (Aplikasi Quantitative Analysis for Management). Malang : Penerbit CV Citra Malang (diakses dari https://www.academia.edu/35168987/Buku_4._Riset_Operasi.pdf?auto=download pada tanggal 23 Juni 2019, pukul 22.16 WIB).

Wardani, Musdalifah dan Lusiyanti, 2018. “Optimalisasi Biaya dan Waktu Pelaksanaan Proyek Pembangunan Perumahan Citraland Palu Menggunakan Metode Program Evaluation dan Review Technique (PERT) - Critical Path Method (CPM) : Studi Kasus Perumahan Citraland Palu", Jurnal Ilmiah Matematika dan Terapan, Vol. 15, No. 2:197-208.

Wijaya, A., 2013. Pengantar Riset Operasi (Edisi 3). Jakarta : Penerbit Mitra Wacana Media. 